Abstracta Iranica Iranica

Revue bibliographique pour le domaine irano-aryen

Volume 28 | 2007

Comptes rendus des publications de 2005

\title{
"Afghanistan Four Years On: An Assessment ». Parameters, vol. 35, 2005, pp. 21-32.
}

\section{Anicée Van Engeland}

\section{(2) OpenEdition}

1 Journals

\section{Édition électronique}

URL : http://journals.openedition.org/abstractairanica/19941

DOI : 10.4000/abstractairanica.19941

ISSN : 1961-960X

Éditeur :

CNRS (UMR 7528 Mondes iraniens et indiens), Éditions de l'IFRI

\section{Édition imprimée}

Date de publication : 15 mai 2007

ISSN : 0240-8910

\section{Référence électronique}

Anicée Van Engeland, « «Afghanistan Four Years On: An Assessment ». Parameters, vol. 35, 2005, pp. 21-32. », Abstracta Iranica [En ligne], Volume 28 | 2007, document 468, mis en ligne le 18 septembre 2007, consulté le 25 septembre 2020. URL : http://journals.openedition.org/abstractairanica/19941 ; DOI : https://doi.org/10.4000/abstractairanica.19941

Ce document a été généré automatiquement le 25 septembre 2020.

Tous droits réservés 


\title{
« Afghanistan Four Years On: An Assessment ». Parameters, vol. 35, 2005, pp. 21-32.
}

\author{
Anicée Van Engeland
}

Si dans son article de 2004 l'A. n'avait pas caché son pessimisme profond quand à la situation en Afghanistan qu'il comparait au Vietnam, il parle en 2005 d'un optimisme réservé. Il compare aujourd'hui l'Afghanistan à la Colombie notamment à cause de l'existence de multiples groupes qui s'affrontent et du trafic de drogue. L'A. dresse alors un bilan comparatif de la situation désespérée en 2003-04 et des améliorations en 2005. Il regarde notamment les différentes actions de l'armée sur le terrain et la lutte contre les seigneurs de guerre et les seigneurs de la drogue pour parvenir à cette conclusion d'un futur optimiste. Il conclut en énumérant les défis à venir dont la lutte contre le crime organisé, les réformes politiques et une meilleure prise en compte des différences culturelles. Il évoque aussi la nécessité de restructurer les équipes militaires étrangères sur place et d'améliorer le commandement conjoint des opérations.

INDEX

Thèmes : 13.2. Afghanistan 
AUTEURS

ANICÉE VAN ENGELAND

Paris 